\title{
Evaluation of a novel vascular graft with a distal bifurcation designed to reduce the development of intimal hyperplasia. Experimental study in a porcine aorta model
}

\author{
Robert Vlachovsky ${ }^{\mathrm{a}}$, Robert Staffa ${ }^{\mathrm{a}}$, Martin Dvorak ${ }^{\mathrm{a}}$, Michal Vlasin ${ }^{\mathrm{b}}$, Marketa Hermanovac, Thomas 0'Briend, \\ Timothy McGloughlin ${ }^{d}$
}

\begin{abstract}
Objective. Abnormal haemodynamics is commonly agreed to be a major contributor to the development of distal anastomotic intimal hyperplasia. A new vascular graft design proposed by computational studies was used to demonstrate its surgical feasibility and to compare it with the conventional graft in a porcine model.

Method. The device was used in 12 eight-month-old pigs, six received the new graft and six had a conventional graft. The proximal graft end was implanted into the aorta, the distal graft end was implanted into the iliac artery. The host artery was ligated in order to simulate occlusion. At 20 weeks after surgery the pigs were killed and the device was excised for histological and morphometric analysis.

Results. In five experimental grafts the reconstruction was occluded due to thrombosis; only one prosthesis was patent showing a minimum of neointimal hyperplasia. In the control group too only three of the six grafts were patent. A histological analysis revealed, as the cause of occlusion, fibrous tissue overgrowth corresponding in structure to neointimal hyperplasia. Differences in the number of obliterations and in occlusion rates between the profiles of the two groups were evaluated using the median test $(P<0.05)$. The results were not statistically significant.

Conclusion. Although mathematical modelling had shown significant haemodynamic benefits of a naturally bifurcated graft, our study did not confirm its superiority over conventionally used prostheses.
\end{abstract}

Key words: animal model, anastomosis, graft design, distal bifurcation, intimal hyperplasia, experimental study, pig

Received: August 25, 2012; Accepted with revision: March 12, 2013; Available online: April 10, 2013 http://dx.doi.org/10.5507/bp.2013.021

${ }^{a}$ Second Department of Surgery, St. Anne's University Hospital in Brno and Faculty of Medicine, Masaryk University, Brno, Czech Republic ${ }^{b}$ Dogs \& Cats Clinic, Faculty of Veterinary Medicine, University of Veterinary and Pharmaceutical Sciences Brno

'First Department of Pathological Anatomy, St. Anne's University Hospital in Brno and Faculty of Medicine, Masaryk University, Brno

${ }^{d}$ Centre for Applied Biomedical Engineering Research, Department of Mechanical and Aeronautical Engineering and Materials and Surface Science Institute, University of Limerick, Limerick, Ireland

Corresponding author: Robert Vlachovsky, e-mail: robert.vlachovsky@fnusa.cz

\section{INTRODUCTION}

The long-term patency rates of synthetic femoral artery bypass grafts remain poor despite great efforts of graft producers and vascular surgeons. Previous studies have reported patency rates for above-knee grafts as low as $62 \%$ at 3 years and $46 \%$ at 5 years $^{1-3}$. Abnormal junction haemodynamics, wall shear stress (WSS), suture line injury and material mismatch are the most frequently mentioned factors responsible for graft failure.

There are several theories suggesting different roles for these factors in typical distal end-to-side anastomosis (ESA) and, even though discussions are still ongoing, abnormal haemodynamics is commonly agreed to be a major contributor to the development of intimal hyperplasia at the junction. The abnormal geometric nature of a distal ESA creates abnormal haemodynamics (disturbed flow with its associated flow separation, stagnation, and recirculation regions) which contributes to the development of intimal hyperplasia by affecting endothelial cells $\mathrm{s}^{4-6}$. Poor patency of prosthetic bypass grafts has resulted in concentrated efforts to improve available prosthetic materials.
A great deal of attention has been focused on surgical modifications (using an interposition vein cuff or patch), materials and coatings, protein modifications, endothelial cell seeding, and nitric oxide modifications of the existing prosthetic grafts to improve graft patency and clinical outcomes. Most of these modifications are designed to improve thrombogenicity, to decrease the development of neointimal hyperplasia, and/or to improve host incorporation and healing. However, all these attempts have yielded limited results, leaving this issue open to further investigation $^{7-35}$.

It has been discovered that flow patterns created by a typical ESA exert abnormal WSS distributions not commonly found in healthy arteries. Studies have shown that wall stress concentrations in the vicinity of an ESA suture line are significantly higher than those occuring at an endto-end anastomosis (EEA) and a healthy artery. Clinical data support these findings, with results suggesting that EEA gives higher patency rates than ESA (ref. $\left.{ }^{36}\right)$.

Identification of these principles and the results of previous studies led our collegues from the Centre for Applied Biomedical Engineering Research (University 
of Limerick, Ireland) to propose a new natural bifurcation bypass graft device - Lamda ${ }^{\odot}$ graft - for the treatment of peripheral arterial occlusive disease. This device has replaced one ESA with two EEAs, using a streamlined bifurcating junction, and thus minimising haemodynamic disturbances leasing to the development of intimal hyperplasia. In addition, the new device provides the type of bifurcation naturally found in the vascular system ${ }^{37}$.

The preliminary evaluations were performed by the Centre for Applied Biomedical Engineering Research, University of Limerick in Ireland, using mathematical modelling and computer simulations involving computational fluid dynamics (CFD model). During the maximum pulse velocity (peak flow), this device streamlines the blood flow to such an extent as to reduce peak WSS magnitudes and WSS gradients in the host artery by $17 \%$ and $53 \%$, respectively. Flow separation along the roof of the host artery distal to the toe is eliminated. During the decelerative phase of the velocity pulse wave, the peak WSS magnitudes and WSS gradients are further reduced by $58 \%$ and $86 \%$, respectively, with a slightly smaller toe flow separation region ${ }^{37}$.

The objective of our study was to introduce this novel design, to demonstrate its surgical feasibility and to compare it with the conventional ESA to confirm that distal anastomosis of a vascular graft can create a bifurcating flow and thus reduce the risk of intimal hyperplasia development.

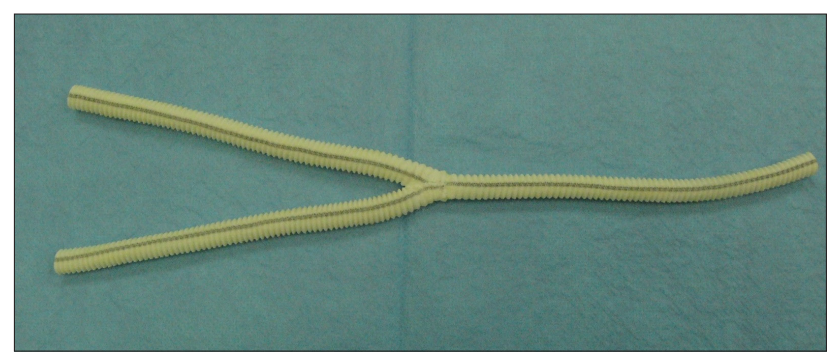

Fig. 1. Geometrical configuration of the experimental graft (normal straight bypass graft with a new distal bifurcation).

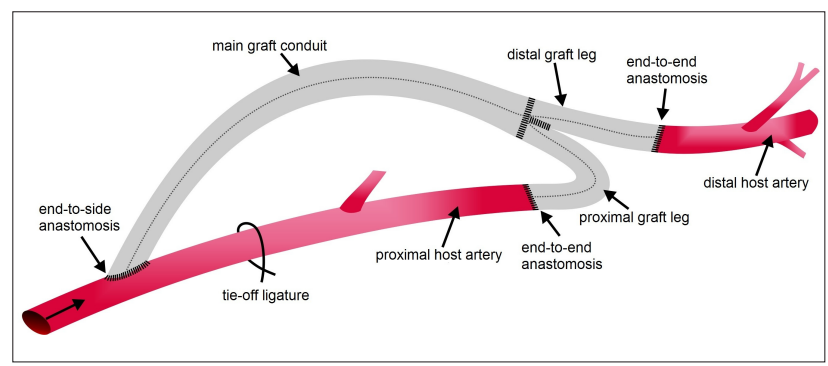

Fig. 2. Experimental graft implantation schematic.

\section{MATERIALS AND METHODS}

The geometric configuration of the device is shown in Fig. 1. It consists of a normal straight bypass graft with a new distal bifurcation added to it. The dacron vascular prosthesis is made of polyester filament yarn and is impregnated with collagen, the graft lumen diameter (experimental and conventional device) is $6 \mathrm{~mm}$.

During the whole study, the animals were fed, handled and housed in accordance with the principles of the Animal Welfare Act. All procedures were carried out with the approval of the Ethics Committee of the University of Veterinary and Pharmaceutical Sciences in Brno (No. 11/07).

The device was implanted into 12 eight-month-old pigs (weight, $58.4 \pm 0.7 \mathrm{~kg}$ ). Six animals (experimental group) received the new graft device and six animals (control group) had a conventional straight vascular graft. The proximal graft end was implanted into the aorta (one ESA in both groups), with the distal graft end or ends implanted into the iliac artery (two EEAs in the experimental group, one ESA in the control group) (Fig. 2 and 3). Anticoagulation therapy with unfractionated heparin (100 IU kg-1) was administered intravenously during the surgical procedure, and the host artery (below the proximal anastomosis) was ligated with standard suture material in order to simulate arterial occlusion. Heparin was reversed with protamine sulfate. Following closure of all soft tissues and the skin, the animals were allowed to recover from anaesthesia. A prophylactic antibiotic (Penicillin G) was given preoperatively and $24 \mathrm{~h}$ postoperatively (Fig. 4 and 5). The pigs fully recovered and were mobile until they were killed at 20 weeks ( 140 days) postoperatively when they weighed approximately $190 \mathrm{~kg}$. In each of the animals killed, the device including the end sections of the aorta and iliac artery was excised for histological assessment and morphometric analysis; together with the end sections it was visually examined for the presence of all anastomoses and potential thrombosis and then fixed in 10\% neutral-buffered formalin for $24 \mathrm{~h}$. Transverse sections were taken at specified points near the distal anastomoses and embedded in paraffin, using standard tissue processing (Fig. 6 and 7). The tissue sections were stained with haematoxylin and eosin and examined by the histopathologist.

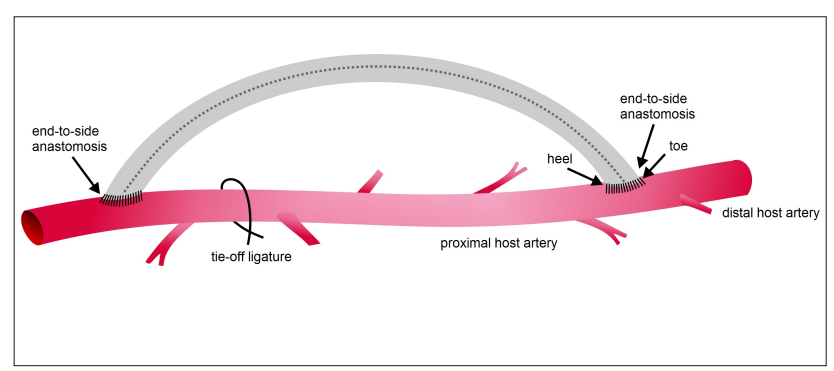

Fig. 3. Conventional graft implantation schematic. 


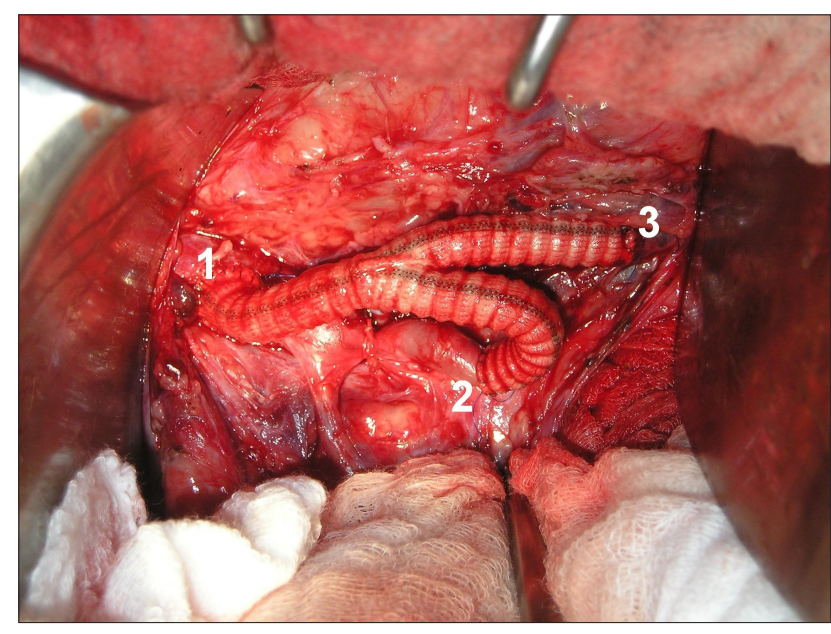

Fig. 4. Experimental graft after the implantation. 1 - proximal anastomosis, 2 - distal anastomosis (proximal graft leg), 3 - distal anastomosis (distal graft leg).

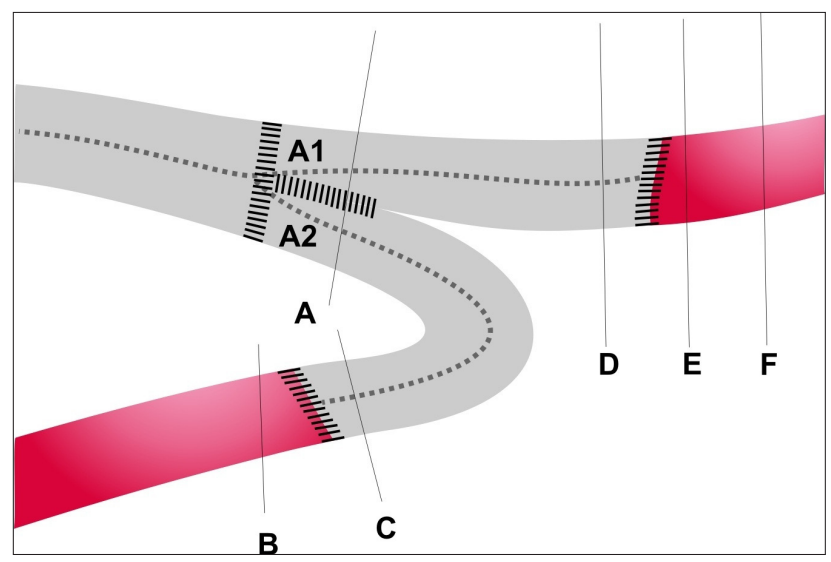

Fig. 6. Experimental graft histology sections (distal anastomosis). A-A: Random section through the junction (A1: distal graft leg, A2:proximal graft leg), B-B: 1 to $2 \mathrm{~mm}$ upstream from proximal junction EEA, C-C: 1 to $2 \mathrm{~mm}$ downstream from proximal junction EEA (proximal graft leg), D-D: $5 \mathrm{~mm}$ upstream from distal junction EEA (distal graft leg), E-E: 1 to 2mm downstream from distal junction EEA (distal host artery), F-F: 10mm downstream from distal junction EEA (distal host artery). EEA - end-to-end anastomosis.

\section{RESULTS}

\section{Surgical implant assessment and histology}

Five outflow arteries (profile $\mathrm{E}$ and $\mathrm{F}$ ) in the experimental group had thrombosis and three of six controls also had graft occlusion due to thrombosis.

In the experimental group, variable degrees of nonsignificant stenosis ( $10 \%$ to $30 \%$ ) of the junction (section $A_{e}$ ) due to fibrous tissue formation were revealed in four cases. Four total obliterations and one severe stenosis $(95 \%)$ of the proximal host artery $\left(\mathrm{B}_{\mathrm{e}}\right)$ were observed. Only in one case the proximal host artery showed a minimal degree of neointima (Fig. 8).

Severe stenosis involving $90 \%$ to $95 \%$ of the distal host artery lumen $\left(E_{e}\right)$ was observed in four pigs , total occlusion was seen in one and a $20 \%$ stenosis was also found

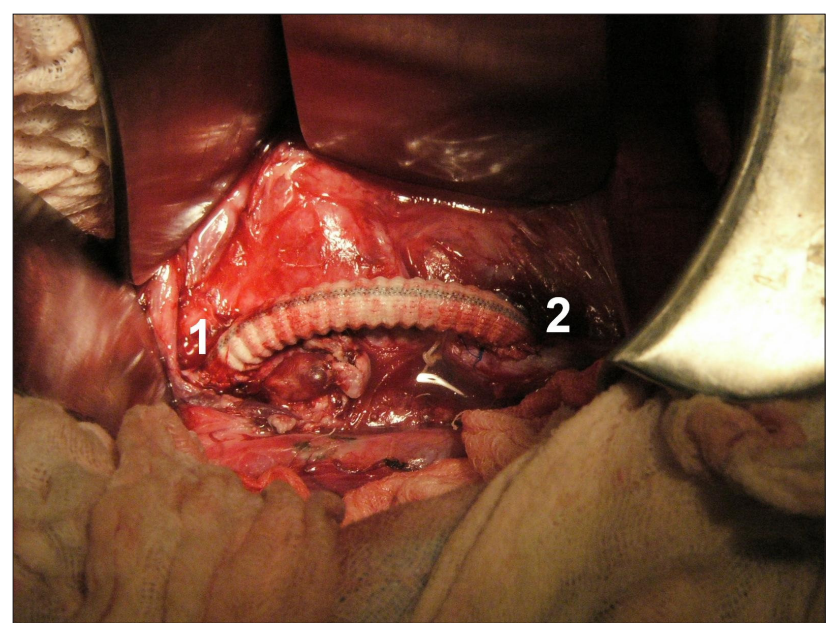

Fig. 5. Conventional graft after the implantation (control group). 1 - proximal anastomosis, 2 - distal anastomosis.

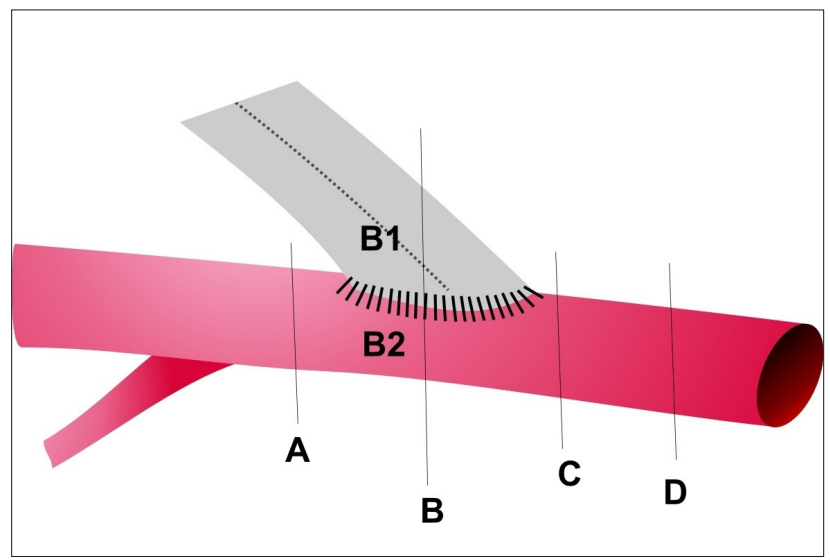

Fig. 7. Conventional graft histology sections (distal anastomosis). A-A: 1 to $2 \mathrm{~mm}$ upstream from heel of ESA (proximal host artery), B-B: Random section through the junction (B1: graft, B2: native artery), C-C: 1 to $2 \mathrm{~mm}$ downstream from toe of ESA (distal host artery), D-D: $10 \mathrm{~mm}$ downstream from toe of ESA (distal host artery). ESA - end-to-side anastomosis.

in one pig (Fig. 9 and 10). Total occlusion in section $\mathrm{F}_{\mathrm{e}}$ was observed in five of six cases. The histological findings revealed a significant degree of neointima with focal disruption of the smooth muscle layer of the media in both the proximal and the distal host artery.

In the control group, significant stenosis of the junction (B2) due to fibrous tissue overgrowth was revealed in all cases (Fig. 11). Variable degrees of significant stenosis ( $60 \%$ to $95 \%$ ) were demontrated in sections $\mathrm{C}_{\mathrm{c}}$ and $\mathrm{D}_{\mathrm{c}}$ of the distal host artery, with a higher degree of neointima in location $\mathrm{D}_{c}$.

\section{Statistical methods and analysis}

The degrees of occlusion of the graft lumen in different sections are expresed as percent of stenosis (Table 1). The data were analysed using the median test (non- 


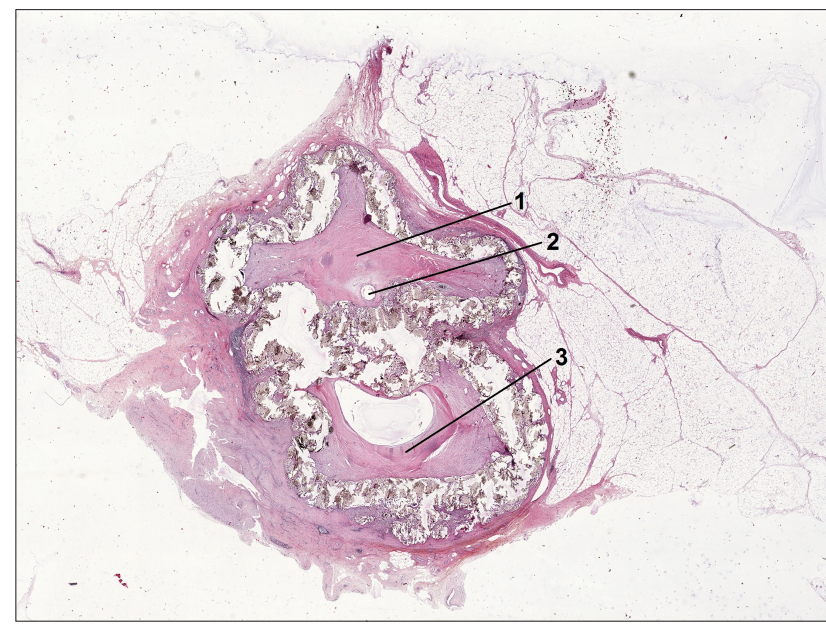

Fig. 8. Random section through the junction, experimental graft histology sections, location A-A (hematoxylin-eosin, original magnification $\mathrm{x} 40$ ). 1 - subtotal graft occlusion, 2 - residual lumen of the distal graft leg, 3 - partial graft occlusion.

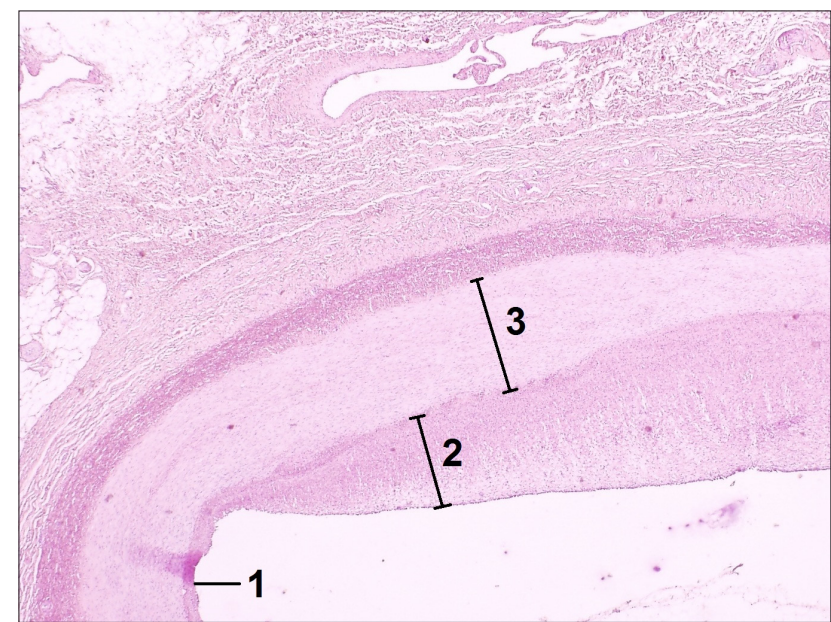

Fig. 10. Representative section of the distal junction of the experimental graft, location D-D (distal graft leg) with neointima (hematoxylin-eosin, original magnification x 40). 1 - intima, 2 - intimal hyperplasia, 3 - smooth muscle layer.

parametric test not assuming any concrete data distribution). The percentages of stenosis in the experimental $\left(\mathrm{C}_{\mathrm{e}}, \mathrm{D}_{\mathrm{e}}, \mathrm{E}_{\mathrm{e}}\right.$ and $\left.\mathrm{F}_{\mathrm{e}}\right)$ and the control group $\left(\mathrm{B}, \mathrm{B} 1_{\mathrm{c}}, \mathrm{C}_{\mathrm{c}}\right.$ and $\left.D_{c}\right)$ were tested $\left(C_{e}\right.$ versus $B 1_{c}, D_{e}$ versus $B_{c}, D_{e}$ versus $B 1_{c}, D_{e}$ versus $B 2_{c}, E_{e}$ versus $C_{c}, F_{e}$ versus $D_{c}$ ). The level of statistical significance was set at $P<0.05$. The testing of all sections (except section $\mathrm{D}_{\mathrm{e}} / \mathrm{B} 2_{\mathrm{c}}$ ) did not show any statistically significant differences between the experimental and control groups (Table 2). For section $\mathrm{D}_{\mathrm{e}} / \mathrm{B} 2$, the intervention effect (reduction in intimal hyperplasia development) was significantly lower in the experimental than the control group $(P=0.021)$.

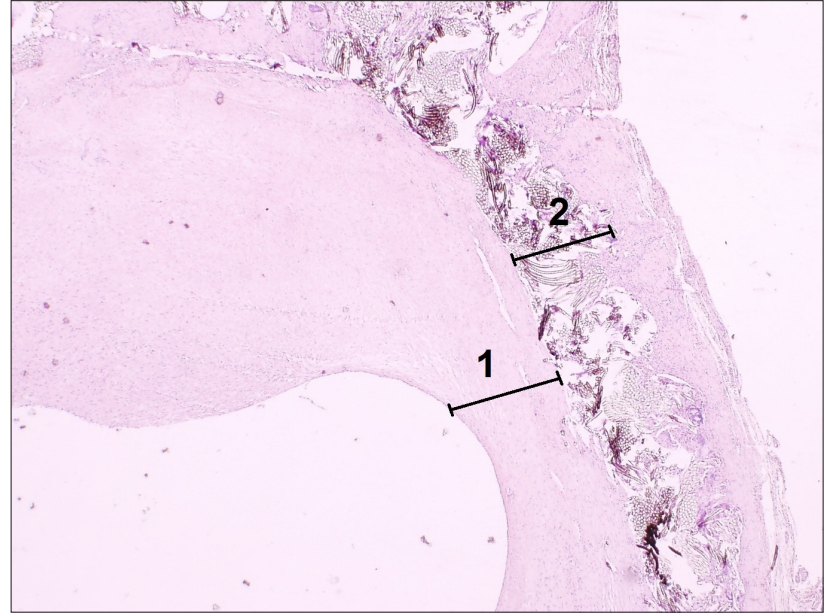

Fig. 9. Representative section of the distal junction of the experimental graft, location C-C (proximal graft leg) with neointima (hematoxylin-eosin, original magnification x 40). 1 intimal hyperplasia, 2 - graft.

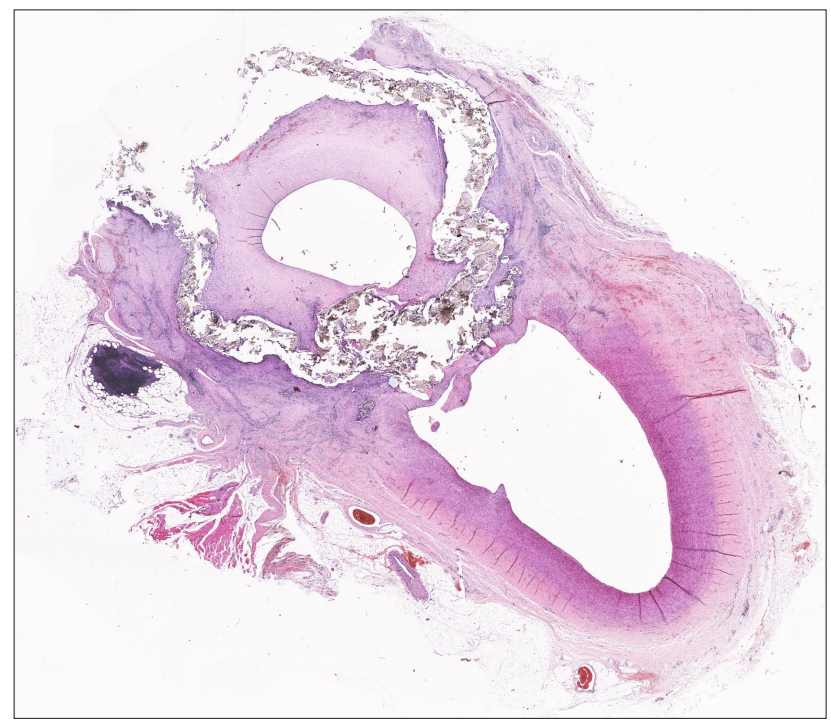

Fig. 11. Random section through the junction, conventional graft histology sections, location B-B, fibrous tissue in the graft lumen (hematoxylin-eosin, original magnification $\mathrm{x} 40$ ).

\section{DISCUSSION}

Mathematical modelling of the proposed graft suggested that the streamlined nature of blood flow through the new junction results in less disturbed haemodynamics within the host artery junction. Abnormal WSS magnitudes and gradients were reduced, and a normal fully developed flow in the distal host artery occurred earlier than in conventional anastomoses. The proposed graft has a design that is relevant to increased patency rates of prosthetic femoral-popliteal bypass grafts. One drawback of the proposed mathematical model is in that flow recirculation and flow separation existing within the prosthesis itself were not taken into consideration. 
Table 1. Degrees of occlusion of the graft lumen in different sections of both groups.

\begin{tabular}{|c|c|c|c|c|c|c|c|c|c|}
\hline Section (experimental group, $n=6$ ) & & $\mathbf{A}_{\mathrm{e}}$ & $\mathbf{A 1} \mathbf{1}_{\mathrm{e}}$ & $\mathrm{A2}_{\mathrm{e}}$ & $\mathbf{B}_{\mathrm{e}}$ & $\mathbf{C}_{\mathrm{e}}$ & $\mathbf{D}_{\mathrm{e}}$ & $\mathbf{E}_{\mathrm{e}}$ & $\mathbf{F}_{\mathrm{e}}$ \\
\hline \multirow{6}{*}{ Degree of occlusion (\%) } & P1 & 0 & 0 & 0 & 100 & 80 & 90 & 95 & 100 \\
\hline & $\mathbf{P 2}$ & 0 & 0 & 0 & 100 & 0 & 0 & 20 & 40 \\
\hline & P3 & 10 & 0 & 20 & 95 & 50 & 40 & 95 & 100 \\
\hline & P4 & 30 & 30 & 30 & 100 & 70 & 70 & 90 & 100 \\
\hline & P5 & 10 & 0 & 20 & 100 & 70 & 5 & 95 & 100 \\
\hline & P6 & 5 & 0 & 10 & 5 & 0 & 0 & 100 & 100 \\
\hline Section (control group, $n=6$ ) & & $\mathbf{A}_{c}$ & & & B1 ${ }_{c}$ & $\mathrm{B2}_{\mathrm{c}}$ & \multicolumn{2}{|c|}{$\mathrm{C}_{\mathrm{c}}$} & $D_{c}$ \\
\hline \multirow{6}{*}{ Degree of occlusion (\%) } & P7 & 95 & & & 0 & 75 & \multicolumn{2}{|c|}{60} & 95 \\
\hline & P8 & 100 & & & 0 & 90 & \multicolumn{2}{|c|}{90} & 95 \\
\hline & P9 & 90 & & & 30 & 80 & \multicolumn{2}{|c|}{90} & 90 \\
\hline & P10 & 95 & & & 60 & 85 & \multicolumn{2}{|c|}{95} & 95 \\
\hline & P11 & 95 & & & 20 & 70 & \multicolumn{2}{|c|}{70} & 85 \\
\hline & P12 & 95 & & & 0 & 80 & \multicolumn{2}{|c|}{85} & 95 \\
\hline
\end{tabular}

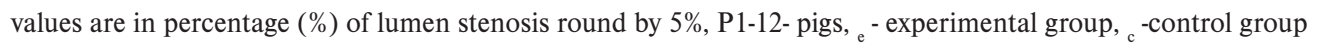

Table 2. Median test results.

\begin{tabular}{ccccccc}
\hline $\begin{array}{c}\text { Section (experimental) } \\
\text { vs. Section (control) }\end{array}$ & $\mathrm{C}_{\mathrm{e}} / \mathrm{B} 1_{\mathrm{c}}$ & $\mathrm{D}_{\mathrm{e}} / \mathrm{B}_{\mathrm{c}}$ & $\mathrm{D}_{\mathrm{e}} / \mathrm{B} 1_{\mathrm{c}}$ & $\mathrm{D}_{\mathrm{e}} / \mathrm{B} 2_{\mathrm{c}}$ & $\mathrm{E}_{\mathrm{e}} / \mathrm{C}_{\mathrm{c}}$ & $\mathrm{F}_{\mathrm{e}} / \mathrm{D}_{\mathrm{c}}$ \\
\hline $\boldsymbol{P}$ & 0.248 & 0.248 & 1 & $0.021^{*}$ & 0.221 & 0.387 \\
\hline
\end{tabular}

$P<0.05,{ }^{*}$ significant result, ${ }_{\mathrm{e}}$ - experimental group, ${ }_{\mathrm{c}}$ - control group

The porcine experimental model was used because of similarities between the human and pig haemocoagulation systems and endothelial injury response. We found a suitable site for implantation of the device in the aortoiliac bed. During implantation the diameter of the vessels complied with the graft diameter. We successfully ligatured the proximal host artery to simulate atherosclerotic blockage. The pigs were regularly observed and no special symptoms of graft occlusion were recorded. Postoperative eventration requiring surgery developed in one pig, and temporary paresis of the left hind leg was found in another pig; both were from the experimental group.

However, our study showed several limitations. First, the characteristics of blood flow created within the proposed graft and their effect on the development of thrombi were not described in the mathematical model, thus thrombus formation could not be fully understood and therefore possible to take into account or deal with in an experimental study. Second, dacron grafts were used in our study. Previous experimental studies have found that low WSS resulting from diverging graft sections can lead to increased intimal hyperplasia inside polytetrafluoroethylene grafts $^{38}$. A similar situation may occur inside dacron grafts and therefore the use of this material is disputable. Third, as in any synthetic prosthesis, the graft used in our study did not provide any buffer for material mismatch between a stiff graft and the compliant artery.
However, correcting abnormal haemodynamics in ESA is recognised as more important than the issue of material mismatch. An idealisation of the model is the fourth limitation. Realistic anastomoses are variable in terms of anastomotic angles, out-of-plane curvatures, graft/artery calibers, flow rates, and lumen surfaces. Previous studies have found significant differences between idealised models and realistic ones ${ }^{37,38}$. Graft failure in our experimental group can be explained by graft kinking. A PTFE graft or an externally supported dacron graft should be able to maintain appropriate curvatures better than the dacron graft used in our study.

Fifth, the interval between device implantation and its explantation (20 weeks) was very long. Piglets grow very fast and their growth acceleration poses a serious problem. Within five months the pig multiplies its weigth and, at the time of graft explantation, our animals weighed about $190 \mathrm{~kg}$. To handle a relatively large animal is complicated and, in addition, noticeable changes in its anatomy and size occur due to intensive growth in its body cavity. These changes could also have influenced the results.

From the surgical point of view, the device relies on two end-to-side anastomoses, which is surgically feasible, but requires good surgical skills and more time than does a conventional distal anastomosis. Also, there is an increased risk of technical complications during the surgical procedure. 
Considering all limitations of the experimental design in this study, it can be concluded that, to establish the device efficacy, a shorter period of study (12 to 14 weeks) and a larger size of animal group will be necessary. A more in-depth study should involve imaging scans of implanted grafts (CT angiography, magnetic resonance angiography) to specify the time of occlusion.

\section{CONCLUSION}

The results of this study did not provide sufficient evidence that the proposed device is suitable for in vivo application or that it improves patency rates by decreasing the development of intimal hyperplasia. Although mathematical modelling has shown significant haemodynamic benefits, this animal study did not confirm our assumption, suggesting that this new graft design with a distal bifurcation probably has no prospects for being used in vascular reconstruction. Efforts to find an optimal type and geometry of ESA will continue.

\section{ACKNOWLEDGEMENTS}

We wish to thank the VUP (Výzkumný ústav pletařský) Inc., Brno, Czech Republic for supplying experimental and conventional grafts free of charge.

Authorship contributions. RV: literature search; RV, TG: manuscript writing; RS, MV, TB, TG: study design; $\mathrm{RV}, \mathrm{RS}, \mathrm{MD}, \mathrm{MV}$ : surgical procedures; RV, MD: data collection; RV, MH: data analysis; RV, RS, MH, TG: data interpretation; RV: statistical analysis, RV: figures; RV: final approval.

Conflict of interest statement: None declared.

\section{REFERENCES}

1. Takagi H, Goto SN, Matsui M, Manabe H, Umemoto T. A contemporary meta analysis of Dacron versus polytetrafluoroethylene grafts for femoropopliteal bypass grafting. J Vasc Surg 2010;52(1):232-6.

2. Devine C, McCollum C. North West Femoro-Popliteal Trial Participants. Heparin-bonded Dacron or polytetrafluorethylene for femoropopliteal bypass: five-year results of a prospective randomized multicenter clinical trial. J Vasc Surg 2004;40(5):924-31.

3. Abbott WM, Green RM, Matsumoto T, Wheeler JR, Miller N, Veith FJ, Suggs WD, Hollier L, Money S, Garrett HE. Prosthetic above-knee femoropopliteal bypass grafting: results of a multicenter randomized prospective trial. Above-Knee Femoropopliteal Study Group. J Vasc Surg 1997;25(1):19-28.

4. O'Brien T, Walsh M, McGloughlin T. On reducing abnormal hemodynamics in the femoral end-to-side anastomosis: the influence of mechanical factors. Ann Biomed Eng 2005;33(3): 309-21.

5. Walsh MT, Kavanagh EG, O'Brien T, Grace PA, McGloughlin T. On the existence of an optimum end-to-side junctional geometry in peripheral bypass surgery - a computer generated study. Eur J Vasc Endovasc Surg 2003;26(6):649-56.

6. O’Brien T, Walsh M, McGloughlin T. Altering end-to-side anastomosis junction hemodynamics: The effect of flow-splitting. Medical Engineering \& Physics 2006;28:727-33.

7. Taylor RS, Loh A, McFarland RJ, Cox M, Chester JF. Improved technique for polytetrafluoroethylene bypass grafting: long term results using anastomotic vein patches. Br J Surg 1992;79:348-54.
8. Raptis S, Miller JH. Influence of vein cuff on polytetrafluoroethylene grafts for primary femoropoliteal bypass. Br J Surg 1995;82:487-91.

9. Karrer L, Duwe J, Zisch AH, Khabiri E, Cikirikcioglu M, Napoli A, Goessl A, Schaffner T, Hess OM, Carrel T, Kalangos A, Hubbell JA, Walpoth $\mathrm{BH}$. PPS-PEG surface coating to reduce thrombogenicity of small diameter ePTFE vascular grafts. Int J Artif Organs 2005;28:993-1002.

10. Jordan SW, Haller CA, Sallach RE, Apkarian RP, Hanson SR, Chaikof $E L$. The effect of a recombinant elastin-mimetic coating of an ePTFE prosthesis on acute thrombogenicity in a baboon arteriovenous shunt. Biomaterials 2007;28:1191-7.

11. San Roman J, Bujan J, Bellon JM, Gallardo A, Escudero MC, Jorge E, de Haro J, Alvarez L, Castillo-Olivares JL. Experimental study of the antithrombogenic behavior of Dacron vascular grafts coated with hydrophilic acrylic copolymers bearing salicylic acid residues. J Biomed Mater Res 1996;32:19-27.

12. Yang J, Motlagh D, Allen J, Webb A, Kibbe M, Aalami O, Kapadia M, Carroll T, Ameer GA. Modulating ePTFE vascular graft host response via citric acid-based biodegradable elastomers. Adv Mater 2006:18:1493-8.

13. Yoneyama T, Sugihara K, Ishihara K, Iwasaki Y, Nakabayashi N. The vascular prosthesis without pseudointima prepared by anti thrombogenic phospholipid polymer. Biomaterials 2002;23:1455-9.

14. Jordan SW, Faucher KM, Caves J, Apkarian R, Rele S, Sun X, Hanson $\mathrm{S}$, Chaikof E. Fabrication of a phospholipid membrane-mimetic film on the luminal surface of an ePTFE vascular graft. Biomaterials 2006;27:3473-81.

15. Bosiers M, Deloose K, Verbist J, Schroe H, Lauwers G, Lansink W Peeters P. Heparin-bonded expanded polytetrafluoroethylene vascular graft for femoropopliteal and femorocrural bypass grafting: 1-year results. J Vasc Surgery 2006;43:313-8.

16. Tseng PY, Rele SS, Sun XL, Chaikof EL. Membrane-mimetic films containing thrombomodulin and heparin inhibit tissue factor-induced thrombin generation in a flow model. Biomaterials 2006;27:2637-50.

17. Wyers MC, Phaneuf MD, Rzucidlo EM, Contreras MA, LoGerfo FW, Quist WC. In vivo assessment of a novel Dacron surface with covalently bound recombinant hirudin. Cardiovasc Pathol 1999;8:153-9.

18. Heise M, Schmidmaier G, Husmann I, Heidenhain C, Schmidt J, Neuhaus P, Settmacher U. PEG-hirudin/iloprost Coating of Small Diameter ePTFE Grafts Effectively Prevents Pseudointima and Intimal Hyperplasia Development. Eur J Vasc Endovasc Surg 2006;32:418-24.

19. Greco RS, Kim HC, Donetz AP, Harvey RA. Patency of a small vessel prosthesis bonded to tissue-plasminogen activator and iloprost. Ann Vasc Surg 1995;9:140-5.

20. Greisler HP, Cziperle DJ, Kim DU, Garfield JD, Petsikas D, Murchan PM, Applegren EO, Drohan W, Burgess WH. Enhanced endothelialization of expanded polytetrafluoroethylene grafts by fibroblast growthfactor type-1 pretreatment. Surgery 1992;112:244-55.

21. Gray JL, Kang SS, Zenni GC, Kim DU, Kim PI, Burgess WH, Drohan W, Winkles JA, Haudenschild CC, Greisler HP. FGF-1 affixation stimulans ePTFE endothelialization without intimal hyperplasia. J Surg Res 1994:57:596-612.

22. Magometschnigg $H$, Kadletz $M$, Vodrazka $M$, Dock W, Grimm M, Grabenwoger M, Minar E, Staudacher M, Fenzl G, Wolner E. Prospective clinical-study with invitro endothelial-cell lining of expanded polytetrafluoroethylene grafts in crural repeat reconstruction. J Vasc Surg 1992;15:527-35.

23. Deutsch M, Meinhart J, Fischlein T, Preiss P, Zilla P. Clinical autologous in vitro endothelialization of infrainguinal ePTFE grafts in 100 patients: a 9-year experience. Surgery 1999;126:847-55.

24. Herring M, Gardner A, Glover J. Single-staged technique for seeding vascular grafts with autogenous endothelium. Surgery 1978;84:498504.

25. Zilla P, Fasol R, Deutsch M, Fischlein T, Minar E, Hammerle A, Krupicka $O$, Kadletz M. Endothelial-cell seeding of polytetrafluoroethylene vascular grafts in humans: a preliminary report. J Vasc Surg 1987;6:535-41.

26. Herring M, Smith J, Dalsing M, Glover J, Compton R, Etchberger $\mathrm{K}$ Zollinger T. Endothelial seeding of polytetrafluoroethylene femoral poplival bypasses: the failure of low-density seeding to improve patency. J Vasc Surg 1994;20:650-5.

27. Jensen N, Lindblad B, Bergqvist D. Endothelial-cell seeded Dacron aortobifurcated grafts: platelet deposition and long-term follow-up. J Cardiovasc Surg 1994;35:425-9. 
28. Fujita $Y$, Hong-De Wu M, Ishida A, Shi Q, Walker M, Hammond WP, Sauvage LR. Accelerated healing of Dacron grafts seeded by preclotting with autologous bone marrow blood. Ann Vasc Surg 1999;13:402-12.

29. Bhattacharya V, McSweeney PA, Shi Q, Bruno B, Ishida A, Nash R, Storb RF, Sauvage LR, Hammond WP, Wu MHD. Enhanced endothelialization and microvessel formation in polyester grafts seeded with CD34 bone marrow cells. Blood 2000;95:581-5.

30. Griese DP, Ehsan A, Melo LG, Kong DL, Zhang LN, Mann MJ, Pratt RE, Mulligan RC, Dzau VJ. Isolation and transplantation of autologous circulating endothelial cells into denuded vessels and prosthetic grafts: implications for cell-based vascular therapy. Circulation 2003;108:2710-5

31. Rotmans Jl, Heyligers JMM, Verhagen HJM, Velema E, Nagtegaal MM, de Kleijn DPV, de Groot FG, Stroes ESG, Pasterkamp G. In vivo cell seeding with anti-CD34 antibodies successfully accelerates endothelialization but stimulates intimal hyperplasia in porcine arteriovenous expanded polytetrafluoroethylene grafts. Circulation 2005; 112:12-8.

32. Mowery KA, Schoenfisch MH, Saavedra JE, Keefer LK, Meyerhoff ME. Preparation and characterization of hydrophobic polymeric films that are thromboresistant via nitric oxide release. Biomaterials 2000;21:9-21.
33. Batchelor MM, Reoma SL, Fleser PS, Nuthakki VK, Callahan RE, Shanley CJ, Politis JK, Elmore J, Merz SI, Meyerhoff ME. More lipophilic dialkyldiamine-based diazeniumdiolates: synthesis, characterization, and application in preparing thromboresistant nitric oxide repase polymeric coatings. J Med Chem 2003;46:5153-61.

34. Jourd'heuil D, Hallen K, Feelisch M, Grisham MB. Dynamic state of $\mathrm{S}$ nitrosothiols in human plasma and whole blood. Free Radic Biol Med 2000;28:409-17.

35. Tyurin VA, Tyurina YY, Liu SX, Bayir H, Hubel CA, Kagan VE. Quantitation of S-nitrosothiols in cells and biological fluids. Methods Enzymol 2002;352:347-60.

36. O'Brien T, Walsh M, Kavanagh E, Finn S, Grace P, McGloughlin T. Surgical feasibility study of a novel polytetrafluorethylene graft design for the treatment of peripheral arterial disease. Ann Vasc Surg 2007;21:611-7.

37. O'Brien T, Grace P, Walsh M, Burke P, McGloughlin T: Computational investigations of a new prosthetic femoral-popliteal bypass graft design. J Vasc Surg. 2005;42(6):1169-75.

38. Loth F, Jones SA, Zarins CK, Giddens DP, Nassar RF, Glagov S. Relative contribution of wall shear stress and injury in experimental intimal thickening at PTFE end-to-side arterial anastomoses. J Biomech Eng 2002;124:44-51. 